\title{
The Efficacy of Vitamin B1, B6, and B12 Forte Therapy in Peripheral Neuropathy Patients
}

\author{
Meyvita Silviana $^{1 *}$, Dodik Tugasworo², Maria Belladonna ${ }^{2}$ \\ ${ }^{1}$ Department of Neurology, Medical Faculty Diponegoro University and Lecturer of Medical Faculty Sultan Agung Islamic \\ University, Semarang, Indonesia \\ ${ }^{2}$ Department of Neurology, Medical Faculty Diponegoro University, Semarang, Indonesia
}

Keywords:

B1, B6, B12 forte

Peripheral neuropathy

TSS

VAS

\begin{abstract}
Background: Peripheral neuropathy can be caused by diabetes mellitus, nutritional deficiencies, entrapment or Carpal Tunnel Syndrome (CTS), and idiopathic.

Objective: To determine the therapeutic efficacy of Vitamin B1, B6, and B12 forte in relieving symptoms of peripheral neuropathy.

Methods: This was pre- and post-experimental study involving patients with moderate peripheral neuropathy (Toronto Clinical Neuropathy Score [TCNS] $\geq 6$ and Michigan Neuropathy Screening Instrument [MNSI] $\geq 7$ ) taken from outpatient neurological clinic of Dr. Kariadi Hospital, Semarang. The patient was prescribed vitamin B1 $100 \mathrm{mg}$, B6 $100 \mathrm{mg}$, and B12 $5000 \mathrm{mcg}$ once daily for 2 months. Evaluation of the numerical pain rating scale in the form of VAS and Total Symptom Score (TSS) was conducted at the first and second month. The VAS score difference test was conducted with the Wilcoxon test and TSS with the Post Hoc test and considered significant if $\mathrm{p}<0.05$.

Results: There were 30 patients aged 18 - 65 years, consisted of $70 \%$ female and $30 \%$ male. The etiology of peripheral neuropathy was idiopathic (40\%), CTS $(26.7 \%)$, DM (23.3\%), and HNP (10\%). There were significant differences of the VAS scale and TSS at every evaluation.

Conclusion: Administration of VitB1, B6, and B12 forte relieved symptoms of moderate peripheral neuropathy with improvement of VAS and TSS scores.
\end{abstract}

drmeyvita.spn@gmail.co

$\mathrm{m}$

Article history:

Received 29-11-2020

Accepted $08-12-2020$

Availableonline10-03-2021

DIMJ, 2021, 2(1), 14-19 DOI: https:// doi.org/10.14710/dimj.v2i1.9549

\section{Introduction}

The definition of neuropathic pain according to the International Association for the Study of Pain (LASP) is pain triggered by a primary lesion or dysfunction of the nervous system and can be caused by compression or infiltration of the nerves depending on its location. It can be defined as an abnormal pain that occurs either as a result of lesions of the peripheral or central nervous system. The prevalence is approximately $1.5 \%$ of all population in the United States. Several diseases can manifest as neuropathic pain, such as trigeminal neuralgia, diabetic neuropathy, spinal cord injury, cancer, stroke, and degenerative neurological disease. $^{1}$

According to Attal et al, the incidence of neuropathic pain was also found to be quite high in Europe, namely $7-8 \%$ of the general population. ${ }^{2}$ In Indonesia, based on the results of a multicenter outpatient study in 14 teaching hospitals conducted by the Pokdi Nyeri PERDOSSI, there were 4,456 cases of pain, $9.5 \%$ were neuropathic pain. In 2012, the cases increased up to $21.8 \%$ based on the study in 13 hospital with more sensitive screening instruments. ${ }^{3}$ Most of subjects were men $(62.1 \%)$ aged 40-60 years with low back pain, carpal tunnel syndrome, frozen shoulder, diabetic neuropathy, and brachialgia. ${ }^{4}$ Neuropathic pain will also affect the quality of life and sleep. Bartley, et al stated that severe and chronic neuropathic pain could increase the risk of anxiety, depression, and decreased quality of life. Choi, et al also reported that of all subjects with neuropathic pain, $67.3 \%$ experienced moderate to severe pain; $43.5 \%$ showed prolonged pain over two years; and $32.4 \%$ suffered from sleep disturbances due to pain, and $22.8 \%$ of patients were dissatisfied with the current management of pain. ${ }^{5}$ 
Pain sensation is normally initiated by activity on afferent unmyelinated $(\mathrm{C}-)$ and thinly myelinated $(\mathrm{A} \delta$-) nerves. These nociceptors will usually not be excited without external stimulation. However, when peripheral nerve lesions occur, these neurons may become abnormally sensitive and develop pathological spontaneous neurological activity. ${ }^{6}$

The spontaneous ectopic activity in damaged nerve cells also indicates an increase of m-RNA expression for voltage-gated sodium channels. This group of sodium channels at ectopic site is responsible for the low threshold of action potential and hyperactivity. This can cause sensitivity to stimuli. Thus, when there is a stimulus that normally does not cause pain, it can immediately cause excessive pain instead. ${ }^{6}$

Lesions in nerve cells will cause regeneration and the growth of neuromas in its proximal part. Abnormal excitation and discharge can appear in this neuroma. This can cause spontaneous abnormal pain in the neuropathic patient. ${ }^{1,6}$

After a nerve cell lesion occurs, the activated macrophage will enter the endoneural blood vessel into the nerve and release cytokines. This inflammatory mediator will induce ectopic activity on damaged nerve cells as well as nearby normal nerve cells. Patients with inflammatory neuropathies will experience very deep pain. ${ }^{6}$

As a consequence of peripheral nociceptor hyperactivity, a dramatic secondary change occurs in the dorsal horn of the spinal cord. Lesions of the peripheral nerves will increase the excitation ability of multireceptors in spinal cord neurons (widedynamic-range neurons). This hyperexcitation is manifested by increased nerve cell activity in response to noxious stimulation, expansion of the receptive neuronal field, and the spread of spinal hyperexcitation to other segments. ${ }^{6}$

Under normal circumstances, neurons in the dorsal horn will receive a strong inhibition from GABA (gamma-aminobutyric acid). In animal study, partial nerve injury will initiate apoptosis of GABA in the superficial portion of the neuron in the dorsal horn. This increases the pain stimulation a neuropathic patient will receive.

Pharmacotherapy that can be used to relieve neuropathic symptoms are anticonvulsants, antidepressants, and neurotropics agent, which include vitamins B1, B6, and B12. Neurotropic vitamins is meant to normalize nerve function by improving metabolic disorders by providing the required intake. ${ }^{3}$ Administration of vitamins B1 (100mg), B6 (100mg), and B12 (200mcg) has been shown to be effective in neuropathic symptoms. ${ }^{7}$ There was still a few data regarding vitamins B1, B6, and B12 as determinants factors of peripheral neuropathy symptoms reduction (pain, burning, tingling, and numbness), as well as the increasing incidence of peripheral neuropathy. Thus, we want to know more about the effects of vitamins B1, B6, and B12 to symptoms of peripheral neuropathy (pain, burning, tingling and numbness).

\section{Methods}

This was a prospective cohort experimental study with consecutive sampling method and a sample size of 30. It was conducted in the outpatient neurology clinic Dr. Kariadi Hospital, Semarang by using a pre and post-test design. Subjects diagnosed with peripheral neuropathy who met the inclusion criteria were given vitamins B1, B6, B1 vitamin B1 (100mg), B6 (100mg), B12 (5000mcg) for 2 months. Evaluation and measurement of the neuropathy degree were carried out on days 0,30 , and 60 . The inclusion criteria were aged 19-64 years; willing to be the subjects; suffering from moderate peripheral neuropathy (MNSI Score $>=7$ ) or TCNS $>=6$; various etiologies, such as diabetes mellitus, nutritional, CTS, idiopathic, etc.) Meanwhile, the exclusion criteria were history of cardiovascular, respiratory, gastrointestinal, hematological, hepatic, renal or endocrine disease (except diabetes mellitus); received methotrexate therapy or other cytostatic drugs; hypersensitivity to Vit B1, B6, B12 forte; suspected of having inherited neuropathy; in pregnancy or breastfeeding; underwent gastrointestinal surgery at least 6 months before the study; had mental illness or in psychiatric therapy; had received NSAIDs, gabapentin, pregabalin, or other anti-inflammatory drugs due to severe neuropathy $($ TCNS $>=12$, VAS $>=7$ ); or had taken oral or parenteral Vit B complex (Vit B1 100-300mg, B6 50-600 mcg, B12 200-5000mcg) for more than 1 week in the last 3 months before the study.

The method of diagnosis used the Michigan Neuropathy Screening Instrument (MNSI) and the Toronto Clinical Neuropathy Score (TCNS). The improvement of neuropathy symptoms was assessed at each visit using the VAS scale and Total Symptom Score (TSS) by assessing symptoms including pain intensity, burning, tingling, and numbness. The total symptoms score data was then compared at each visit to see if there were significant reductions in neuropathy symptoms after the use administration of vitamin B1, B6 and B12 therapy. The VAS score difference test was conducted with Wilcoxon test and TSS with the Post Hoc test, and considered to be significant if $\mathrm{p}<0.05$. 


\section{Results}

In this study (Table 1), it was found that the subjects were predominantly female $(70 \%)$ and idiopathic etiology $(40 \%)$ with a mean age of 52.9 years. The etiology of all the subjects consisted of carpal tunnel syndrome (26.7\%), diabetes mellitus (23\%), and hernia nucleus pulposus (10\%), respectively. There were also patients with risk factors that could affect the outcome of the study, they were hypertension $(60 \%)$, smoking $(30 \%)$, alcohol $(3.3 \%)$, and consumption of tea or coffee $(100 \%)$.

Table 1. Characteristics of the subjects with peripheral neuropathy

\begin{tabular}{|c|c|c|c|c|}
\hline Variable & $\mathrm{F}$ & $\%$ & $\begin{array}{c}\text { Mean } \pm \\
\text { SD }\end{array}$ & $\begin{array}{l}\text { Median } \\
\text { (Range) }\end{array}$ \\
\hline \multicolumn{5}{|l|}{ Sex } \\
\hline Male & 9 & 30 & & \\
\hline Female & 21 & 70 & & \\
\hline Age & & & $\begin{array}{l}52.90 \pm \\
5.79\end{array}$ & $\begin{array}{c}55(36- \\
61)\end{array}$ \\
\hline \multicolumn{5}{|l|}{ Etiology } \\
\hline $\mathrm{DM}$ & 7 & 23.3 & & \\
\hline HNP & 3 & 10 & & \\
\hline CTS & 8 & 26.7 & & \\
\hline Idiopathic & 12 & 40 & & \\
\hline Subjective MNSI & & & $\begin{array}{c}7.90 \pm \\
1.09\end{array}$ & $\begin{array}{c}8(6- \\
10)\end{array}$ \\
\hline Objective MNSI & & & $\begin{array}{l}1.20 \pm \\
6.66\end{array}$ & $1(0-3)$ \\
\hline TCNS & & & $\begin{array}{l}7.83 \pm \\
1.05\end{array}$ & $\begin{array}{c}8(6- \\
11)\end{array}$ \\
\hline Hypertension & 18 & 60 & & \\
\hline Smoking & 9 & 30 & & \\
\hline Alcohol & 1 & 3.3 & & \\
\hline $\begin{array}{l}\text { Tea and coffee } \\
\text { consumption }\end{array}$ & 30 & 100 & & \\
\hline VAS 1 & & & $\begin{array}{c}3.75 \pm \\
0.58\end{array}$ & $\begin{array}{c}3.8(3.1 \\
-4.8)\end{array}$ \\
\hline TSS 1 & & & $\begin{array}{c}7.37 \pm \\
1.18\end{array}$ & $\begin{array}{c}7.32 \\
(5.65- \\
10.31)\end{array}$ \\
\hline VAS 2 & & & $\begin{array}{c}2.71 \pm \\
0.48\end{array}$ & $\begin{array}{c}2.75 \\
(2.1- \\
3.6)\end{array}$ \\
\hline TSS 2 & & & $\begin{array}{c}5.57 \pm \\
0.98\end{array}$ & $\begin{array}{l}5.49(4 \\
-7.98)\end{array}$ \\
\hline VAS 3 & & & $\begin{array}{c}2.19 \pm \\
0.41\end{array}$ & $\begin{array}{l}2.2(1.5 \\
-2.8)\end{array}$ \\
\hline TSS 3 & & & $\begin{array}{c}3.87 \pm \\
1.04\end{array}$ & $\begin{array}{c}3.83 \\
(2.33- \\
5.65)\end{array}$ \\
\hline VAS $1-2$ & & & $\begin{array}{c}-1.04 \pm \\
0.66\end{array}$ & $\begin{array}{l}-1(-2.4 \\
-0.1)\end{array}$ \\
\hline TSS $1-2$ & & & $\begin{array}{c}-1.80 \pm \\
1.15\end{array}$ & $\begin{array}{l}-1.8(-4 \\
-0.22)\end{array}$ \\
\hline VAS $2-3$ & & & $\begin{array}{c}-0.52 \pm \\
0.24\end{array}$ & $\begin{array}{c}-0.5(- \\
1.3-0)\end{array}$ \\
\hline
\end{tabular}

\begin{tabular}{|c|c|c|}
\hline TSS $2-3$ & $\begin{array}{c}-1.70 \pm \\
0.81\end{array}$ & $\begin{array}{c}-.166(- \\
3.66-(- \\
0.66))\end{array}$ \\
\hline VAS $1-3$ & $\begin{array}{c}-1.56 \pm \\
0.65\end{array}$ & $\begin{array}{c}-1.55(- \\
2.9-(- \\
0.4))\end{array}$ \\
\hline TSS $1-3$ & $\begin{array}{c}-3.50 \pm \\
1.39\end{array}$ & $\begin{array}{c}-3.3(- \\
6.32-(- \\
1.32))\end{array}$ \\
\hline
\end{tabular}

Table 2 showed that there were significant differences in the mean VAS and TSS score of all subjects with peripheral neuropathy of various etiologies who received B1, B6, B12 forte therapy, both from monitoring at the first month compared to the time of diagnosis $(p<0.05)$, the second month compared to the first month ( $\mathrm{p}<0.05)$, as well as the second month compared to the start of the study ( $\mathrm{p}$ $<0.05)$.

Table 2. The differences of VAS and TSS score among visits

\begin{tabular}{|c|c|c|c|c|c|}
\hline \multirow{2}{*}{ Variable } & \multirow{2}{*}{$\begin{array}{c}\text { Mean } \pm \text { SD } \\
\text { (Range) }\end{array}$} & \multirow{2}{*}{$\mathrm{P}$} & \multicolumn{3}{|c|}{$\mathrm{P}$ value between visits } \\
\hline & & & $1-2$ & $2-3$ & $1-3$ \\
\hline \multicolumn{6}{|l|}{ VAS } \\
\hline VAS 1 & $\begin{array}{c}3.75 \pm 0.58 \\
(3.1-4.8)\end{array}$ & & & & \\
\hline VAS 2 & $\begin{array}{c}2.71 \pm 0.48 \\
(2.1-3.6)\end{array}$ & $0.00 * *$ & $0.00 * \varepsilon$ & $0.00 * \AA$ & $0.00 * f$ \\
\hline VAS 3 & $\begin{array}{c}2.19 \pm 0.41 \\
(1.5-2.8)\end{array}$ & & & & \\
\hline \multicolumn{6}{|l|}{ TSS } \\
\hline TSS 1 & $\begin{array}{c}7.37 \pm 1.18 \\
(5.65- \\
10.3)\end{array}$ & & & & \\
\hline TSS 2 & $\begin{array}{c}5.57 \pm 0.98 \\
(4.00- \\
7.98)\end{array}$ & $0.00 * \S$ & $0.00 * \sharp$ & $0.00 * \$$ & $0.00 * \$$ \\
\hline TSS 3 & $\begin{array}{c}3.87 \pm 1.04 \\
(2.33- \\
5.65)\end{array}$ & & & & \\
\hline
\end{tabular}

Note: * Significant; ${ }^{¥}$ Friedman; ${ }^{£}$ Wilcoxon; ${ }^{\S}$ Repeated Anova; $¥$ Post Hoc

Table 3 showed an improvement in VAS score both for patients who have risk factors or not.

Table 3. The effects of risk factors to VAS score among visits

\begin{tabular}{lccc}
\hline \multirow{2}{*}{ Variable } & \multicolumn{3}{c}{ P value of VAS between visits } \\
\cline { 2 - 4 } & $1-2$ & $2-3$ & $1-3$ \\
& $\mathrm{p}$ & $\mathrm{P}$ & $\mathrm{p}$ \\
\hline Hypertension & $0.137^{\star}$ & $0.829^{\star}$ & $0.120^{\ddagger}$ \\
Smoking & $0.958^{\S}$ & $0.088^{\star}$ & $0.649^{\star}$ \\
Alcohol & $0.643^{\star}$ & $0.141^{\star}$ & $0.384^{\star}$ \\
consumption & & &
\end{tabular}




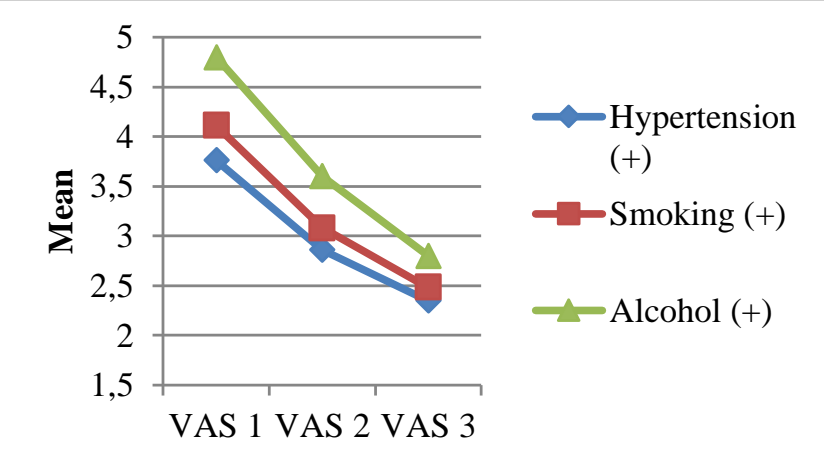

Figure 1. The effect of risk factors to VAS score among visits

Table 4 showed that there was an improvement in the TSS score and significant differences of TTS in subjects who had a risk factor of smoking. In subjects with hypertension, there was a significant difference at the first visit compared to after receiving Vit B1, B6, B12 Forte for 2 months.

Table 4. The effects of risk factors to TSS among visits

\begin{tabular}{lccc}
\hline \multirow{2}{*}{ Variable } & \multicolumn{3}{c}{ P value of TSS between visits } \\
\cline { 2 - 4 } & $1-2$ & $2-3$ & $1-3$ \\
& $\mathrm{p}$ & $\mathrm{P}$ & $\mathrm{p}$ \\
\hline Hypertension & $0.202^{\S}$ & $0.098^{\ddagger}$ & $0.020^{*}$ \\
Smoking & $0.024^{*}$ & $0.005^{*}$ & $0.000^{*}$ \\
Alcohol & $0.415^{\ddagger}$ & $1.000^{\ddagger}$ & $0.418^{\ddagger}$ \\
consumption & & &
\end{tabular}

Note: * Significant; ${ }^{\S}$ t-test; ${ }^{\ddagger}$ Mann Whitney; ${ }^{¥}$ Spearman’s;

"I Kruskal Wallis; ANOVA

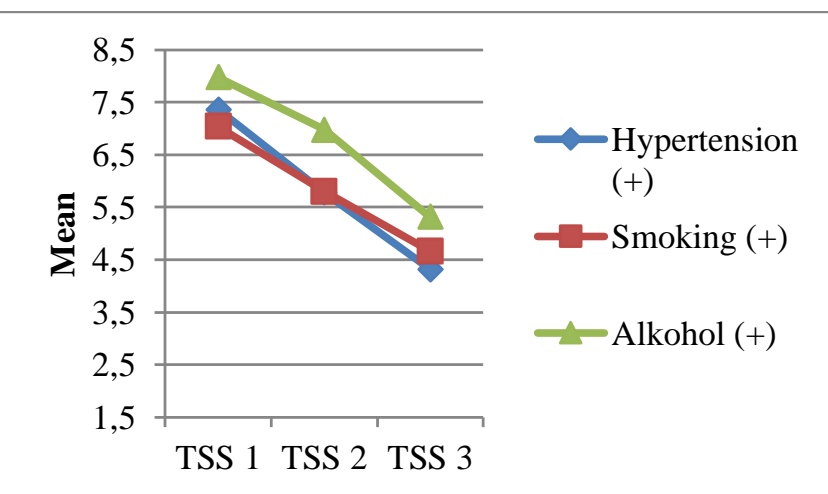

Figure 2. The effect of risk factors to TTS among visits

\section{Discussion}

The hypothesis in this study was administration of vitamins B1, B6 and B12 Forte had an effect on reducing the symptom score of VAS or TSS in patients with peripheral neuropathy. TTS was chosen because we could directly observe 4 symptoms at once in neuropathic patients.

The total number of patients in this study was 30 patients with 21 female (70\%) and 9 male (30\%). This was similar to Katulanda et al. which stated that the prevalence of patients suffering from diabetic neuropathy in developing countries was predominantly female. ${ }^{8}$ This is also consistent with other studies on the epidemiology of neuropathic pain by Fillingim et al. and Bartley et al. They found that sensitivity to pain occurred more frequently in female than male. ${ }^{9,10}$ This could be the result of many factors, including biopsychosocial, hormones, and pain coping. Meanwhile, the mean age of the subjects in this study was 52 years. It was similar to a study by Perhimpunan Dokter Spesialis Saraf Indonesia which was conducted on 5,000 patients in hospitals in Jakarta, Surabaya, and Medan, which reported that $81 \%$ of neuropathy attacked patients who were 40 years old and older. ${ }^{3}$ Lautenbacher et al. and Wandner et al. indicated that old age patients had a higher pain sensitivity than younger. These studies also stated that the perception of pain or discomfort showed less consistent results in the younger age patients. ${ }^{11,12}$

Smoking is a modifiable risk factor for diabetic neuropathy. According to the Center for Disease Control and Prevention (CDC), smoking will increase nerve damage in diabetic patients causing complications of peripheral neuropathy with symptoms of numbness, pain, lack of coordination, and weakness in hands and feet. ${ }^{13}$ Tesfaye et al. stated that the incidence of diabetic neuropathy was multifactorial related to metabolic disorders, oxidative stress, and growth factor deficiency. ${ }^{13}$ Wiggin et al. also reported that high triglyceride was the only clinical parameter correlated with the loss of nerve fiber density in diabetic neuropathy patients. ${ }^{14}$ This was because therapy was meant to control blood lipid level and administration of vitamin combination for 2 weeks helped in decreasing the total symptom score. ${ }^{14}$ Theoretically, hypertension and high blood sugar can accelerate microvascular and macrovascular complications that lead to nerve fiber damage and causing neuropathic symptoms. ${ }^{15}$ This is in line with this study, which showed that there was a significant relationship between the difference of TSS among visits and smoking as risk factor. Meanwhile, there was no statistically significant association between the risk factors of smoking, hypertension, and alcohol consumption with the VAS difference among visits although there was an improvement in the VAS score.

This study did not measure the patient's blood sugar levels. According to the National Institute of Diabetes and Digestive and Kidney Diseases (NIDDK), the best way to prevent and improve neuropathy was by controlling blood sugar levels within normal limits because it helped maintain nerve fibers. ${ }^{16}$ 
All samples in this study were given combination therapy of vitamins B1 $(100 \mathrm{mg}), \mathrm{B} 6(100 \mathrm{mg})$, and B12 (5000 mcg) forte once a day. In general, there were no serious side effects from the administration this vitamin. Three of the 30 samples had reactions to vitamin B therapy, including nausea and vomiting. Vitamin B12 plays a role in the metabolism of fatty acids which are useful in repairing nerve myelin fibers. The role of vitamin B1 is to initiate nerve impulses from coenzymes and B6 is involved in the synthesis of neurotransmitters so that both of them can improve neuropathy ${ }^{17}$.

This study showed that there was a decrease in TSS after giving combination therapy of vitamins B1, B6 and B12 either after 30 days or 60 days. This was in accordance with the Farvid et al. They conducted a study with administration of B1 (10 mg), B2 (10 mg), B6 $(10 \mathrm{mg})$, biotin $(200 \mathrm{mg}), \mathrm{B} 12(10 \mathrm{mg})$ and folic acid (1 $\mathrm{mg})$ supplementation and assessed by Michigan Neuropathy Screening Instrument (MNSI). It obtained a significant decrease of MNSI score from 3.96 to $1.00(\mathrm{p}=0.01) .{ }^{18} \mathrm{~A}$ significant result was also found by Rizvi et al., a combination of vitamins B1 $(100 \mathrm{mg})$, B6 (100mg), and B12 (200mcg) was effective in 177 (57\%) of 310 patients with diabetic peripheral neuropathy. ${ }^{7}$

\section{Conclusion}

The administration of vitamins B1, B6 and B12 forte therapy has been shown to have an effect on the clinical outcome of patients with peripheral neuropathy with various etiologies. However, further research is still needed to assess other risk factors such as dyslipidemia, blood sugar levels, etc., comparing between etiologies, and the magnitude of the effect based on existing risk factors.

\section{Ethical Approval}

The ethical approval for this study was issued by the Health Research Ethics Committee of Medical Faculty Diponegoro University /EC/FK.UNDIPRSDK/04 Feb/2016

\section{Conflicts of Interest}

There is no conflict of interest.

\section{Funding}

All financial resources are borne by the researcher and sponsor.

\section{Author Contributions}

The conceptualization, writing preparation, validation, formal analysis, investigation, and data curation of this study was supported by Dodik
Tugasworo. While, methodology, writing, and reviewing was supported by Maria Belladonna.

\section{Acknowledgments}

This work is supported by the Department of Neurology, Faculty of Medicine, Diponegoro University.

\section{References}

1. Cruccu G, Truini A. A review of Neuropathic Pain: From Guidelines to Clinical Practice. Pain Ther. 2017;6(Suppl 1):35-42. doi:10.1007/s40122-017-0087-0

2. Attal N, Cruccu G, Baron R, et al. EFNS guidelines on the pharmacological treatment of neuropathic pain: 2010 revision. Eur J Neurol. 2010;17(9):1113-e88. doi:10.1111/j.1468 1331.2010.02999.x

3. Perhimpunan Dokter Spesialis Saraf Indonesia (PERDOSSI) dan MERCK Indonesia. 2012. Siaran Pers: Neuropati Perifer Diabetes. http://www.merck.co.id/country.id/id/images/Si aran Pers N5000 Makassar_4Oct_tcm663_104054.pdf?Version=/

4. Purwata T, Anggraini H, Anwar Y, et al. Characteristics of neuropathic pain in Indonesia: A hospital based national clinical survey. Neurol Asia. 2015;1:389-394.

5. Choi YS, Kim DJ, Lee KY, et al. How does chronic back pain influence quality of life in koreans: a cross-sectional study. Asian Spine J. 2014;8(3):346-352. doi:10.4184/asj.2014.8.3.346

6. Baron R. Neuropathic pain: a clinical perspective. Handb Exp Pharmacol. 2009;(194):3-30. doi:10.1007/978-3-540-790907_1

7. Rizvi A, Ahmad A, Rizvi Z. Efficacy of combination of vitamin B1, B6 and B12 in management of diabetic peripheral neuropathy. Pakistan J Med Heal Sci. 2013;7:801-803.

8. Katulanda P, Ranasinghe P, Jayawardena R, Constantine GR, Sheriff MHR, Matthews DR. The prevalence, patterns and predictors of diabetic peripheral neuropathy in a developing country. Diabetol Metab Syndr. 2012;4(1):21. doi:10.1186/1758-5996-4-21

9. Fillingim RB, King CD, Ribeiro-Dasilva MC, Rahim-Williams B, Riley 3rd JL. Sex, gender, and pain: a review of recent clinical and experimental findings. J Pain. 2009;10(5):447485. doi:10.1016/j.jpain.2008.12.001

10. Bartley EJ, Fillingim RB. Sex differences in pain: a brief review of clinical and experimental 
findings. $B r \quad J$ Anaesth. 2013;111(1):52-58. doi:10.1093/bja/aet127

11. Lautenbacher S, Peters JH, Heesen M, Scheel J, Kunz M. Age changes in pain perception: A systematic-review and meta-analysis of age effects on pain and tolerance thresholds. Neurosci Biobehav Rev. 2017;75:104-113. doi:10.1016/j.neubiorev.2017.01.039

12. Wandner LD, Scipio CD, Hirsh AT, Torres CA, Robinson ME. The perception of pain in others: how gender, race, and age influence pain expectations. $J$ Pain. 2012;13(3):220-227. doi:10.1016/j.jpain.2011.10.014

13. Tesfaye S, Vileikyte L, Rayman G, et al. Painful diabetic peripheral neuropathy: consensus recommendations on diagnosis, assessment and management. Diabetes Metab Res Rev. 2011;27(7):629-638. doi:10.1002/dmrr.1225

14. Wiggin TD, Sullivan KA, Pop-Busui R, Amato A, Sima AAF, Feldman EL. Elevated triglycerides correlate with progression of diabetic neuropathy. Diabetes. 2009;58(7):16341640. doi:10.2337/db08-1771

15. Inceu G, Roman G, Veresiu IA. Assessment of Nerve Fibers Dysfunction Through Current
Perception Threshold Measurement in Diabetic Peripheral Neuropathy. In: ; 2017:25-30. doi:10.1007/978-3-319-52875-5_6

16. National Institute of Diabetes and Digestive and Kidney Disease (NIDDK). Diabetic Neuropathies: The Nerve Damage of Diabetes. https://www.niddk.nih.gov/healthinformation/diabetes/overview/preventingproblems/nerve-damage-diabetic-neuropathies. Published 2013.

17. Pazirandeh S, Burns DL. Overview of water soluble vitamins. https://www.uptodate.com/contents/overviewof-water-solublevitamins?sectionName=VITAMIN (ASCORBIC ACID)\& topicRef $=1$ 18084\&anchor $=$ H54\&sourc e=see_link. Published 2009.

18. Farvid MS, Homayouni F, Amiri Z, Adelmanesh F. Improving neuropathy scores in type 2 diabetic patients using micronutrients supplementation. Diabetes Res Clin Pract. 2011;93(1):86-94.

doi:10.1016/j.diabres.2011.03.016 